\title{
RAIO X
}

\section{DAS TELECOMUNICAÇÕES}

\section{Oito grupos dominam as TVs no Brasil}

\section{Empresários e políticos registram as concessões de emissoras de rádio e TV em nome de familiares para violar a lei e garantir, assim, o monopólio privado dos meios de comunicação}

O Código Brasileiro de Telecomunicações, criado há 31 anos para disciplinar as concessões de rádio e TV no país, virou obra de ficção.

A legislação proíbe a concentração de mercado, estabelecendo que nenhuma entidade ou pessoa pode ter participação em mais de dez emissoras de TV em todo o país, das quais cinco, no máximo, devem ser VHF (identificadas pelos canais até o número 13 ).

A família do empresário Roberto Marinho (Rede Globo) participa como acionista em 17 emissoras de TV, das quais 15 são VHF.

Segundo o cadastro oficial do $\mathrm{Mi}$ nistério das Comunicações, os Marinho têm dez concessões próprias de TV (oito VHF e duas UHF, ou seja, com canais de número superior a 13) e são os sócios de mais quatro emissoras VHF no Paraná, de duas em São Paulo e de uma em Minas Gerais.

A família Sirotsky (Rede RBS) tem 13 concessões de TV VHF e é acionista de mais uma emissora, no Espírito Santo.

As famílias Saad (Bandeirantes), Abravanel (SBT - Sistema Brasileiro de

\section{A AUTORA}

Elvira Lobato

Jornalista da Folha de S.Paulo.
Televisão, Grupo Sílvio Santos) e Câmara (do grupo Anhangüera, da Região CentroOeste) também estouram o teto permitido de cinco concessões de VHF no país.

A Bandeirantes tem nove concessões VHF, o SBT tem oito (mais uma UHF) e a família Câmara tem sete.

\section{BRECHAS NA LEI}

Os oligopólios se formaram através de uma brecha deixada na lei. Ela fixou os limites por entidade e por acionista, mas não previu um artifício simples: o registro de concessões em nome de vários membros da família.

No Estado de São Paulo, há duas concessões de TV em nome do empresário Roberto Marinho: na capital (TV Globo de São Paulo, canal 5) e em Sorocaba (TV Aliança Paulista, canal 33).

Roberto Irineu Marinho, um de seus filhos, é sócio da TV Vale do Paraíba (canal 17, UHF) e da TV Bauru (canal 2).

José Roberto, outro filho, é acionista da TV São José do Rio Preto (canal 2) e da TV Globo de São Paulo, junto com o pai.

O terceiro filho, João Roberto Marinho, é sócio da Empresa Paulista de Televisão nas emissoras de Campinas (canal 12) e de Ribeirão Preto (canal 7). 
Família Marinho (Rede Globo)

\begin{tabular}{lcc}
\hline Estado & $\begin{array}{c}\text { Concessões } \\
\text { de TV }\end{array}$ & $\begin{array}{c}\text { Concessões } \\
\text { de rádio }\end{array}$ \\
\hline BA & - & 2 \\
DF & 1 & 2 \\
MG & 3 & 3 \\
PE & 1 & 2 \\
PR & 4 & 1 \\
RJ & 1 & 6 \\
SP & 7 & 4 \\
\hline TOTAL & 17 & 20
\end{tabular}

O decreto lei 236/67, que completou o Código Brasileiro de Telecomunicações, diz que nenhuma entidade ou acionista pode ter mais do que duas emissoras de TV VHF por Estado.

Roberto Marinho e seus três filhos estão individualmente dentro da lei, mas, vistos como membros de um mesmo grupo empresarial, ultrapassam em quase duas vezes o limite de participação em emissoras de VHF.

O decreto 236 também diz (no Artigo 12 , parágrafo $7^{\circ}$ ) que as concessionárias de radiodifusão não podem ser subordinadas a outras entidades que se constituam com a finalidade de estabelecer direção ou orientação única, através de cadeias ou de associaçōes de qualquer espécie.

\section{Família Sirostky (RBS)}

\begin{tabular}{lcc}
\hline Estado & $\begin{array}{c}\text { Concessões } \\
\text { de TV }\end{array}$ & $\begin{array}{c}\text { Concessões } \\
\text { de rádio }\end{array}$ \\
\hline ES & 1 & - \\
RS & 10 & 14 \\
SC & 3 & 7 \\
\hline TOTAL & 14 & 21
\end{tabular}

\section{Concentração}

Com isto, o legislador quis, à época, impedir a concentração de mercado.

A própria denominação de rede, utilizada pelas concessionárias (Rede Globo, Rede Bandeirantes, etc.) prova que o princípio da desconcentração é desrespeitado.

O decreto diz (no mesmo Artigo 12) que as entidades que ultrapassarem os limites máximos de concessões por Estado e âmbito nacional têm dois anos para vender o excedente e se enquadrar nos limites legais.

A punição para a desobediência ao Artigo 12 é severíssima: cassação da emissora.

No Rio Grande do Sul, a família Sirotsky (da RBS, afiliada ${ }^{1}$ da Globo), conseguiu controlar dez emissoras VHF no Estado: Uruguaiana (canal 13), Santa Rosa (canal 6), Santa Maria (canal 12), Santa Cruz do Sul (canal 6), Rio Grande (canal 9), Porto Alegre (canal 12), Pelotas (canal 4). Bagé (canal 6), Caxias do Sul (canal 8) e Erechim (canal 2).

As concessões estão distribuídas por vários membros da família: Ione (viúva do fundador, Maurício Sirotsky), Jaime Sirotsky (presidente do Conselho Administrativo da RBS, irmão do fundador), Nelson Sirotsky (presidente da RBS), José Pedro Sirotsky (vice-presidente), filhos e genros.

Além das dez emissoras próprias no Rio Grande do Sul, a rede RBS arrendou duas TVs no interior do Estado: Cruz Alta (canal 3) e Passo Fundo (canal 7). Com isto, tem domínio quase absoluto do mercado do Rio Grande do Sul.

A RBS tem ainda três concessões de TV em Santa Catarina e 30\% da TV Cachoeiro, de Cachoeiro do Itapemirim, no Espírito Santo.

\footnotetext{
1. Estação local de rádio e TV que se vincula a uma rede ou cadeia para transmitir programas em comum, sem deixar de ser uma empresa independente. (N.E.)
} 
Família Abravanel - SBT

(Grupo Sílvio Santos)

\begin{tabular}{ccc} 
Estado & $\begin{array}{c}\text { Concessões } \\
\text { de TV }\end{array}$ & $\begin{array}{c}\text { Concessões } \\
\text { de rádio }\end{array}$ \\
\hline
\end{tabular}

\begin{tabular}{lll}
\hline DF & 1 & - \\
SP & 4 & - \\
PA & 1 & - \\
RJ & 2 & - \\
RS & 1 & - \\
\hline
\end{tabular}

TOTAL

9

0

\section{Única vez}

$\mathrm{O}$ único caso que se tem registro de aplicação rigorosa da lei ocorreu no final da década de 60.

O empresário Ulisses Ferreira Júnior, de São Paulo, foi obrigado a vender cerca de 20 emissoras de rádio, que estavam em seu nome, até se enquadrar nos limites do decreto.

\section{Família Saad (Rede Bandeirantes)}

\begin{tabular}{ccc}
\hline Estado & $\begin{array}{c}\text { Concessões } \\
\text { de TV }\end{array}$ & $\begin{array}{c}\text { Concessões } \\
\text { de rádio }\end{array}$ \\
\hline
\end{tabular}

\begin{tabular}{lcc}
\hline SP & 4 & 15 \\
DF & 1 & - \\
BA & 1 & 3 \\
MG & 1 & 1 \\
PR & 1 & - \\
RJ & 1 & 1 \\
RS & - & 1 \\
\hline
\end{tabular}

TOTAL

9

21

As redes, que se formaram a partir de então, usaram o artifício do registro das concessões em nome de parentes. O Ministério controla a concentração pelo $\mathrm{CPF}$ do acionista e não pelo sobrenome ou pelo cargo que ocupa.

Há desrespeito também ao princípio da desconcentração das emissoras de rádio FM. Pela legislação, uma mesma empresa (ou acionista) não pode ter mais do que seis FMs em âmbito nacional.
Os Sirotsky têm 14, os Saad têm oito, e os Marinho têm sete, de acordo com os registros do Ministério das Comunicações.

O expediente é o mesmo utilizado para as TVs: distribuir as concessões entre parentes, como pais, filhos, irmãos, mulheres e cunhados.

\section{OUTROS PAÍSES IMPÕEM LIMITES}

Nos Estados Unidos é proibido um jornal diário possuir uma estação de rádio ou televisão na mesma comunidade em que a publicação circula.

A lei entrou em vigor em 1975. Os casos que ainda existem são anteriores à lei.

$\mathrm{Na}$ Itália, a lei $\mathrm{n}^{\circ} 223$, de agosto de 1990, impôs limites à propriedade de órgãos de mídia de diferentes tipos. Nenhuma pessoa que controle jornais com mais de $16 \%$ da circulação nacional pode receber uma licença para estações nacionais de televisão.

Aqueles que controlam empresas que publicam jornais diários com circulação superior a $8 \%$ do total nacional podem receber licença para possuírem apenas uma estação de televisão, operando em nível nacional.

Família Câmara (Grupo Câmara)

\begin{tabular}{lcc}
\hline Estado & $\begin{array}{c}\text { Concessões } \\
\text { de TV }\end{array}$ & $\begin{array}{c}\text { Concessões } \\
\text { de rádio }\end{array}$ \\
\hline DF & - & 1 \\
GO & 5 & 5 \\
TO & 2 & 7 \\
\hline TOTAL & 7 & 13
\end{tabular}

OS MARINHO SÃO

DONOS DO MAIOR IMPÉRIO

O cadastro de sócios das emissoras de rádio e TV do Ministério das Comunicações mostra que o mercado brasileiro tem um grande império da radiodifusão sob o comando da família do empresário Roberto Marinho. 
O mapeamento das concessões registradas no Ministério das Comunicações mostra que a família Marinho é a que tem o maior número de geradoras nos mercados de maior poder aquisitivo.

Ela tem emissoras em Brasília, Recife, Rio de Janeiro, quatro próprias e duas em sociedade no Estado de São Paulo, duas próprias e uma em sociedade em Minas Gerais e mais quatro em sociedade no Estado do Paraná.

O SBT, do grupo Sílvio Santos, tem nove TVs em nome de empresas da família Abravanel (sobrenome de Sílvio Santos).

O grupo tem seis concessões na região Sudeste (quatro em São Paulo e duas no Rio de Janeiro), uma no Rio Grande do Sul, uma em Brasília e outra no Pará.

A família Saad, da Rede Bandeirantes, tem quatro concessões de TV no Estado de São Paulo e uma em cada uma das seguintes capitais: Curitiba, Brasília, Belo Horizonte, Rio e Salvador.

\section{Família Bloch (Grupo Manchete)}

\begin{tabular}{lcc} 
Estado & $\begin{array}{c}\text { Concessões } \\
\text { de TV }\end{array}$ & $\begin{array}{c}\text { Concessões } \\
\text { de rádio }\end{array}$ \\
\hline BA & - & 1 \\
CE & 1 & - \\
DF & - & 1 \\
MG & 1 & - \\
PE & 1 & 1 \\
RJ & 1 & 2 \\
SP & 1 & 1 \\
\hline TOTAL & 5 & 6
\end{tabular}

Os Saad e os Sirotsky concentram o maior número de rádios: cada uma das famílias tem 21 emissoras.

O grupo Manchete, de acordo com o cadastro do Ministério das Comunicações, tem três emissoras no Sudeste (São Paulo, Belo Horizonte e Rio de Janeiro) e duas no Nordeste (Fortaleza e Recife).

Segundo a pesquisa Intermeios (da revista Meio \& Mensagem), a verba publi- citária veiculada pelas televisões no ano passado foi de cerca de US\$1,3 bilhão, e a das rádios ficou em torno de US\$ 100 milhões.

A estimativa do mercado é de que a Globo e suas afiliadas concentram mais de $60 \%$ da verba publicitária em TV e que o SBT e suas afiliadas ficaram com cerca de $20 \%$.

Família Daou (TV do Amazonas)

\begin{tabular}{lcc}
\hline Estado & $\begin{array}{c}\text { Concessões } \\
\text { de TV }\end{array}$ & $\begin{array}{c}\text { Concessões } \\
\text { de rádio }\end{array}$ \\
\hline AC & 1 & 1 \\
AP & 1 & 1 \\
AM & 1 & 2 \\
RO & 1 & - \\
RR & 1 & - \\
\hline TOTAL & 5 & 4
\end{tabular}

\section{Impérios regionais}

Os grupos regionais de radiodifusão mais fortes do país são afiliados da Rede Globo. As emissoras dos políticos mais influentes também, o que aumenta o poder político de Roberto Marinho.

No Sul do país o mercado é dominado pela família Sirotsky, proprietária da Rede RBS, afiliada da Globo. Os membros da família têm, no total, dez concessões de TV no Rio Grande do Sul (mais duas sob sua gestão por acordo comercial) e três em Santa Catarina.

Fora do Sul, a família Sirotsky só aparece como acionista em uma emissora: TV Itapemirim, no Cachoeiro do Itapemirim. Seu parceiro na empresa é o grupo Gazeta, do Espírito Santo, também afiliado da Globo.

Na Região Norte, o Grupo Rádio e TV do Amazonas - da família Daou tem geradoras, afiliadas da Globo, em Roraima, Rondônia, Acre, Amapá e Amazonas. É o grupo mais forte da região.

No Centro-Oeste, os dois grupos mais fortes - família Câmara, que atua em 
Goiás e Tocantins, e a família Zahran (Mato Grosso do Sul e Mato Grosso) - são também afiliados da Globo. A família Câmara tem sete concessões de TV e 12 rádios, e a Zahran tem quatro TVs e uma rádio.

\section{Família Zahran (Grupo Zahra)}

\begin{tabular}{lcc}
\hline Estado & $\begin{array}{c}\text { Concessões } \\
\text { de TV }\end{array}$ & $\begin{array}{c}\text { Concessões } \\
\text { de rádio }\end{array}$ \\
\hline MS & 3 & 1 \\
MT & 1 & 1 \\
\hline TOTAL & 4 & 2
\end{tabular}

No Nordeste o único grupo que tem concessões em mais de um Estado é o da família Jereissati (grupo Verdes Mares): duas rádios e uma TV no Ceará (afiliada da Globo), uma rádio no Rio de Janeiro e outra em Alagoas.

Na maior parte dos Estados nordestinos, os grupos locais fortes são vinculados a políticos.

$\mathrm{Na}$ Bahia, o deputado federal Pedro Irujo Yaniz (PMDB) tem duas concessões de TV (afiliadas do SBT) e quatro emissoras de rádio. Seu filho Luís Pedro Irujo é sócio da família Marinho nas duas rádios Globo do Estado.

A principal emissora baiana afiliada da Globo é a TV Bahia, que tem entre seus sócios o deputado federal (PFL) Luiz Eduardo Magalhães, filho do ex-ministro das Comunicações e ex-governador Antônio Carlos Magalhães - ACM (hoje senador), e César Mata Pires, genro de ACM.

Família Jereissati (Grupo Verdes Mares)

\begin{tabular}{lcc}
\hline Estado & $\begin{array}{c}\text { Concessões } \\
\text { de TV }\end{array}$ & $\begin{array}{c}\text { Concessões } \\
\text { de rádio }\end{array}$ \\
\hline $\mathrm{AL}$ & - & 1 \\
$\mathrm{CE}$ & 1 & 2 \\
$\mathrm{PE}$ & - & 1 \\
$\mathrm{RJ}$ & - & 1 \\
\hline
\end{tabular}

TOTAL

1
No Sergipe, a família do senador Albano Franco (PSDB) é o grupo de radiodifusão mais forte: tem duas emissoras de TV (uma afiliada da Globo e outra do SBT) e três concessões de rádio.

\section{Ex-presidentes}

Em Alagoas e no Maranhão, as afiliadas Globo pertencem às famílias de dois expresidentes da República.

No Maranhão, a afiliada Globo é a TV Mirante, registrada em nome dos filhos do ex-presidente José Sarney (1985-90), que possuem também quatro emissoras de rádio.

Em Alagoas, a emissora afiliada é a TV Gazeta, que tem entre seus sócios o expresidente Fernando Collor de Mello (1990-92).

No Rio Grande do Norte, a afiliada Globo - TV Cabugi - tem entre seus sócios o ex-ministro da Integração Regional, Aluízio Alves.

Condomínio Associados

\begin{tabular}{lcc}
\hline Estado & $\begin{array}{c}\text { Concessões } \\
\text { de TV }\end{array}$ & $\begin{array}{c}\text { Concessões } \\
\text { de rádio }\end{array}$ \\
\hline DF & 1 & 2 \\
GO & 1 & - \\
MG & 1 & 3 \\
PE & - & 2 \\
RN & - & 2 \\
\hline TOTAL & 3 & 9
\end{tabular}

PRINCIPAIS POLÍTICOS (E FAMILIARES) SÓCIOS DE EMISSORAS

\section{Ex-Presidente}

Fernando Collor de Mello (PRN)

Alagoas (1990-92)

televisão: TV Gazeta de Alagoas (canal 7) - afiliada Globo 
rádios: Arapiraca $(\mathrm{FM})$, Maceió $(\mathrm{OM})$, Maceió (FM)

\section{Ministro}

José Eduardo de Andrade Vieira (PTB-PR) Agricultura (1995) e ex-ministro da Indústria, Comércio e Turismo (1992-94)

televisão: TV Londrina (canal 13) - não instalada

rádios: Arapoti $(\mathrm{OM})$, Londrina $(\mathrm{OM})$, Londrina (FM)

\section{Ex-Ministros}

Aluizio Alves (PMDB-RN)

Integração Regional

televisão: TV Cabugi (canal 11) - afiliada Globo

rádios: Mossoró (OM), Natal (OM)

\section{Deputado Federal e \\ Ex-Presidente da Câmara \\ Inocêncio de Oliveira (PFL) \\ televisão: TV Asa Branca (canal 4) - afilia- da Globo \\ rádios: Afogados do Ingazeira (FM), Ser- ra Talhada (OM), Serra Talhada (FM)}

\section{Governadores}

\section{Albano Franco (PSDB-SE)}

televisão: TV Sergipe (canal 4) - afiliada Globo; TV Atalaia (canal 8) - afiliada SBT rádios: Atalaia (OM), Sergipe (FM), Atalaia (FM), Simão Dias (OM)

\section{Secretário do Desenvolvimento Regional}

Cícero Lucena (PMDB-PB - ex-governador da Paraíba)

rádio: João Pessoa (OM)
Ex-Governadores

João Alves Filho (PFL-SE)

televisão: TV Aracaju (canal 13) - afiliada

Manchete

rádios: Propriá (FM), Aracaju (OM), Aracaju (FM)

Carlos Santos (PP-PA)

televisão: TV Marajoara (canal 10) - ainda não instalada, TV Sistema Clube do Pará (canal 2) - ainda não instalada

rádios: Belém (FM), Belém (OT), Belém (OM)

Geraldo Bulhões (PSC-AL) rádios: Maceió (FM), Arapiraca (OM), Rio Largo (OM), Santana do Ipanema (OM)

Orestes Quércia (PMDB-SP) ${ }^{2}$

televisão: TV Princesa D'Oeste (Campinas-canal 6) - afiliada SBT; TV do Povo (Santos-canal 12) - afiliada SBT rádios: Campinas (OM), Campinas (FM), São Paulo (FM), Sorocaba (FM)

José Ribamar Fiquene (PFL-MA)

televisão: TV Curimã (canal 7) - afiliada SBT

rádio: Imperatriz (FM)

\section{Senadores}

\section{José Sarney (PMDB-MA)}

Presidente do Congresso Nacional e ex-presidente da República (1985-90)

televisão: TV Mirante (canal 10) - afiliada Globo

rádios: Caxias (OM), Pinheiro (OM), São Luís (FM) e Timon (OM).

Antônio Carlos Magalhães (PFL-BA)

Ex-governador da Bahia (1990-94) e exministro das Comunicações (1985-90)

televisão: TV Bahia (canal 11) - afiliada Globo 
José Agripino Maia (PFL-RN)

televisão: TV Tropical (canal 8) - afiliada Manchete rádios: Currais Novos (OM), Mossoró (OM), Natal (FM)

Jáder Barbalho (PMDB-PA)

Ex-governador do Pará (1990-94)

televisão: TV RBA (canal 13) - afiliada Manchete; TV Marajoara (canal 10) ainda não instalada; TV Sistema Clube (canal 2) ainda não instalada

rádios: SNC Marabá (FM), SNC Marabá (OM), Cubano Marabá (OM), Carajás (FM), Belém (FM), Rádio Clube (OT), Clube (OM)

Édison Lobão (PFL-MA)

Ex-governador do Maranhão

Rádios: Barra do Corda (OM) e Impera$\operatorname{triz}(\mathrm{FM})$

Odacir Soares (PFL-RO)

televisão: TV Porto Velho (canal 13) - afiliada Bandeirantes rádios: Cacoal (OM), Pimenta Bueno (OM), Porto Velho (FM), Presidente Médici (FM), Rolim Moura (FM), Ouro Preto do Oeste (FM)

Júlio Campos (PFL-MT)

televisão: TV Rondon (canal 8) - afiliada Bandeirantes, Rádio e TV Brasil (canal 8) - afiliada Bandeirantes rádios: Várzea Grande (OM), Várzea Grande (FM), Diamantino (OM)

Hugo Napoleão (PFL-PI)

Ex-ministro

rádios: Poty Teresina (OM) e Poty (FM)

Mansueto de Lavor (PMDB-PE)

Rádio: Salgueiro (OM)

Gilberto Miranda Batista (PMDB-AM)

televisão: TV Rio Negro (canal 13), afiliada Bandeirantes 